\title{
Prospective scenarios for the full solar energy development in Malaysia
}

\begin{abstract}
The limited availability of fossil energy carriers and environmental impact of energy consumption demand mid- and long-term strategies both for the rational use of energy and for increased renewable energy utilization. Despite the establishment of the National Energy Policy, there is still an obstacle in reaching those objectives and targets. In the 7th Malaysia Plan for instance, the government has highlighted that a third of the Government's total allocation of RM469 million for rural electrification programmes under the has been allocated for the provision of solar powered installations for rural and remote communities. This paper outlines a detailed description of various existing solar technologies, the understanding of each technology and its associated challenges, which will provide a suitable basis to recognize advantages and drawbacks in its implementation in Malaysia. The paper finally justifies some of the barriers in promoting the full scale utilization for the solar energy in Malaysia.
\end{abstract}

Keyword: Energy consumption demand, Renewable energy, Rural electrification, Solar powered installations, Solar technologies 